\title{
Management at the Edge of Opportunity
}

\author{
Bob Budd
}

"Why do species become extinct? Because they first become rare. Why do they become rare? Because of shrinkage in the particular environments which their particular adaptations enable them to inhabit. Can such shrinkage be controlled? Yes, once the specifications are known. How known? Through ecological research. How controlled? By modifying the environment with those same tools and skills already used in agriculture and forestry."

\section{Aldo Leopold \\ The Land Ethic}

As people, we tend to see in shades of black-and-white, to place values on our world, and to demand results. Even in nature, we expect to have sure, certain outcomes from our actions. We decide what is important and what is not, placing value-laden terms such as "good," or "fair," or "poor" on landscapes as well as species. For those of us who live on the land, the world rarely catches hues of black or white, only occasional shades of darker or lighter grey.

On any given day, I will encounter many things, from peregrine falcons soaring over my head, to rattlesnakes beneath my feet, to the new life of a black-baldy calf in my arms. On the slopes where I work, seven species of rare plants make a living among the representative plant communities that define my existence and that of other species. Sagebrush, bitterbrush, yarrow, and balsamroot scent the air. Soon it will be a mix of later season plants that integrate themselves into the seasons of my senses. The riparian areas in my temporary care are a mixture of constantly mobile sand and silt, contradicted by stable stands of willow and birch older than the ranch house, even ancient juniper fence posts. There are frogs in the stream now, a revelation. The sound of that first frog's belly hitting the water was riveting as a gunshot. We raced through the snagging, snarling roses to see this green messenger, and danced in the sedges like children!

The 35,000 acres upon which I work are owned by The Nature Conservancy, and we use cows to achieve multiple objectives associated with conserving biological diversity in the southern Wind River Mountains. Some assume there must be some contradiction in terms, in mission, in realities. Nothing could be further from the truth.

"Given the knowledge and the desire, this idea of controlled wild culture or 'management' can be applied not only to quail and trout, but to any living thing from bloodroots to Bell's vireos. Within the limits imposed by the plant succession, the soil, the size of the property, and the gamut of the seasons, the landowner can raise any wild plant, fish, bird, or mammal he wants to. A rare bird or flower need remain no rarer than the people willing to venture their skill in building it a habitat."

Aldo Leopold

The Land Ethic
Every day in the Rocky Mountain West, hundreds of thousands of acres are converted from open ranchland to housing, recreational venues, and uses which wildlife and natural things do not seem to comprehend. When we assess threats to plant communities and the species that depend upon them, few compare with this current race to fragment habitats. Yet, we often find ourselves mired in debate over uses of the landscape-emotional, sometimes irrational extensions of our personal biases which may forsake the task at hand. Conservation is the task at hand, and how we get there is as much a function of conserving people who can do this job daily, as it is a necessity to "save all the pieces."

I work with grazing animals, and people who like grazing animals. Most of the animals are cows, but some are bison. Some are animals native to this land. Others are not. They are grazing animals, defined in most dictionaries as "animals that eat grass." I work on public lands and private lands, from alpine forest to cold desert. I would rather think of the land in its ecological sense than by its political identity-it seems more honest and fair. Ridges don't run on grid lines. Creeks and rivers follow the terrain and not a map. Mule deer could care less about the politics.

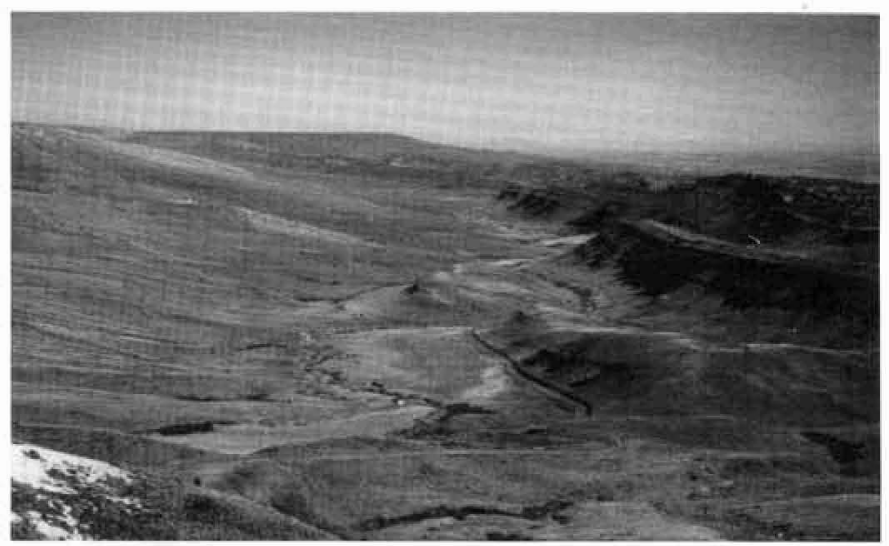

Today, there is constant debate about grazing animals, or at least those that are cows and sheep. Some would remove livestock from all public lands. Others would be happy to remove livestock from the landscape altogether (including me, at the end of calving or the height of weaning). But, how do you measure success when that objective is achieved?

Just down the road lies four hundred acres of ranchland where livestock have been removed. It began simply enough, with reductions in numbers of animals on public lands. And the banker waited, and he wanted his money back, as he should. It mattered not that the number of cows to make the payment were now being concentrated on the private lands, where streams and springs were plentiful, and the rancher 
tried to make the land carry the load, to make it work, as he should. A deal is a deal. When cows would no longer make the payments, and the land was tired, it was plowed to make way for a cash crop that might return more per acre. Fertilizers were jabbed into the soil, and chemicals kept the crops "pure." In time, willow stands and chokecherry bushes were removed. The land was leveled, and drained, and made better for crops like corn or wheat. But, even that did not sustain the people on the land, and in time, 400 acres became 40 lots.

This must be a model of success, for there are no cattle on this ranch anymore. Now, there are 40 houses, 40 sheds, 40 roads, 40 septic tanks, 40 wells, 40 sets of trash barrels, 40 haystacks, 40 irrigation ditches, 40 fences, 80 dogs, 80 cats, 80 cars that run, 80 cars that will run no more, 120 horses that never get ridden, a handful of llamas, 240 sheep, and a bunch of rabbits in cages. There is leafy spurge and knapweed, houndstongue and toadflax. When it rains, brown water runs from the roads to the creek. Sometimes, it makes a light tan foam where it enters the stream. No one fishes here much.

Last week, with several hundred cattle as witnesses, my eight-year-old son caught a fish as long as his arm on a willow battered fly he finally threw with finesse. The next day, he saddled his own horse at dawn and moved cattle to the mountains. To that man, choices were very simple. We can choose to "save" something like the stream he loves by taking away something else he loves, or we can work to care for the whole. If we truly wish to manage for landscapes in which wild things can thrive, to offer them a future, then we must think on a larger scale. We cannot take a traditional, reductionist view of science and impose it on nature. As the saying goes, "don't try to teach a pig to sing-it's frustrating for you, and it annoys the pig."

To get there, we really don't have that many tools at our disposal. We often jump first to technology, that "thing" humans run to whenever we venture out of black-and-white land, that thing which moves us to select quick-fixes to our problems, so that we might get back to the current murder on our latest version of the television. Technology is an answer, but it is not the only answer. At times, the technology solution is driven by a reactionary chain that addresses more symptoms than problems. And, at times, we do not sufficiently work out effects and unintended consequences of technological advance, leading us to take two steps forward-one back, or one forward-and two back.

We have fire, removed from our box of tools long ago, long enough that we now must understand the need to make fuel loads appropriate to the places where we might burn. Fire is essential, and yet, we must be careful to make fire work in a natural sense, at a time when fires should burn, in fuels that aren't laden with the baggage of decades or generations of suppression. Fire has even become the short-term goal in some cases, leading us to use other tools so that fire itself becomes a usable force in the future.

There is rest, long used, often abused. In ecosystems where I work, grazing animals have been part of the landscape since the Pleistocene, and in fact, are now some of the species we worry most about. Like uncertain doctors, we prescribe rest

\section{... livestock are an economic force that main- tains vast landscapes by generating a profit for people who love the land, and want nothing more than the chance to continue making a living by caring for natural landscapes.}

and monitor symptoms, often finding that the patient recovers miraculously to our wisdom. But, few of us follow the patient home, and when it begins to lose vigor to a place where it cannot recover, we look only to the latest episode, and not the life of the system. Land is a living thing. When we restrain it to save it, we must at least check in once in awhile to see that all is well. We may find that our prescription is akin to paralysis, a total lack of energy in the system, a slow death we don't see or care enough to reverse. However, when used in a managed grazing program, rest can be an extremely effective tool, paving the way for fire, living organisms, animal use, and other combinations of management which ultimately point us toward our goal for a given piece of land.

Living organisms are often not immediate change agents, and humans are woefully inadequate in understanding relationships, so we scurry to things which look to be better and faster ways of achieving immediate satisfaction. Even if we can understand that grasshoppers live in a seven-or elevenyear cycle, we are still not satisfied to connect the hoppers to the sage grouse to the alfalfa to the weevils to water to soil to pesticides to heat or cold. Use of this tool can be rewarding and instructive, and keeping it in mind can help us comprehend both biological diversity and the need to think on a larger scale.

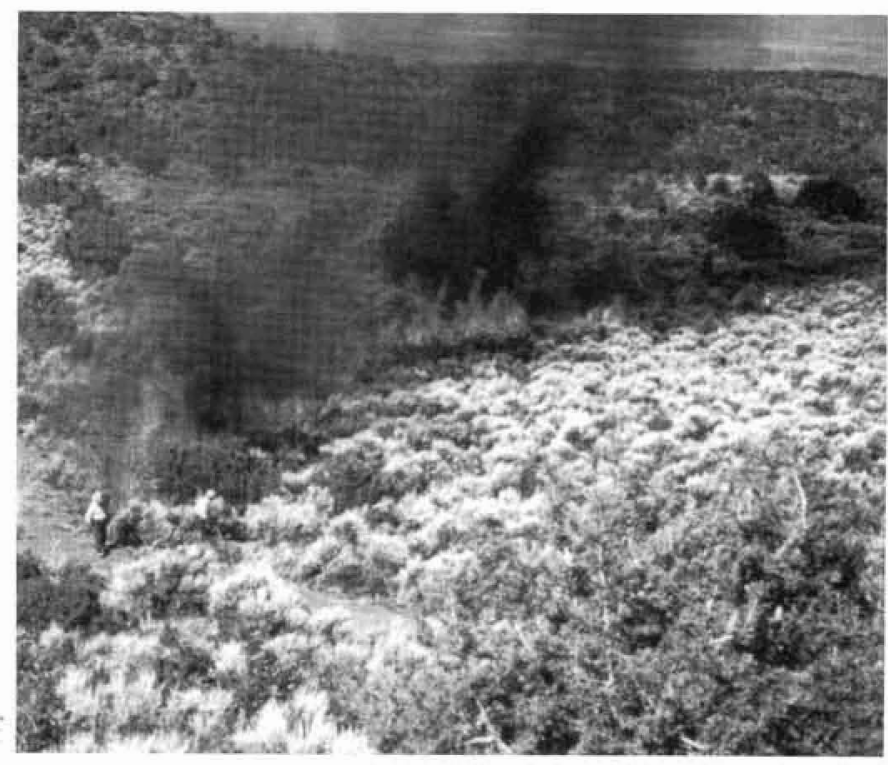

And then there is this thing called grazing animals...a concept that ventures into images of black and white. At Red Canyon Ranch, we often ask people to name three grazing animals. Adults uniformly point out cow, horse and sheep. Children see beyond paradigms of adult knowledge and cry out, "goose!, deer!, buffalo!, grasshopper!, elk!, mole!, moun- 


\section{We know that big, native ungu- lates did not follow a plan de- rived by Lewis and Clark.}

tain sheep!, rabbit!, gopher!, prairie dog!, cow!" Arms raised high, other arm around the neck to hold the uplifted firm, they see this essential tool for what it is. One girl raised her arm, nose, eyebrows, and bangs to be noticed, then shouted out, "APHIDS - the cows of ants!"

We focus most of our attention on the tool of grazing, and associated response, for a number of reasons. First, it is an ancient and prevalent force in the landscapes in which we work-our natural systems evolved with grazing animals, and while the current user may not be exactly the same as those through history, it is one we can manage with an incredible degree of sensitivity.

Secondly, livestock are an economic force that maintains vast landscapes by generating a profit for people who love the land, and want nothing more than the chance to continue making a living by caring for natural landscapes. These are the people of whom Leopold speaks in The Land Ethic when he suggests that the "harmonious integration" of bread and beauty "can make farming not only a business but an art; the land not only a food factory but an instrument for self expression, on which each can play music of his own choosing." Livestock and people who raise them are fibers in the cultural tapestry of western communities, a source of stability to local economies and traditions, but more so, those who hold the line

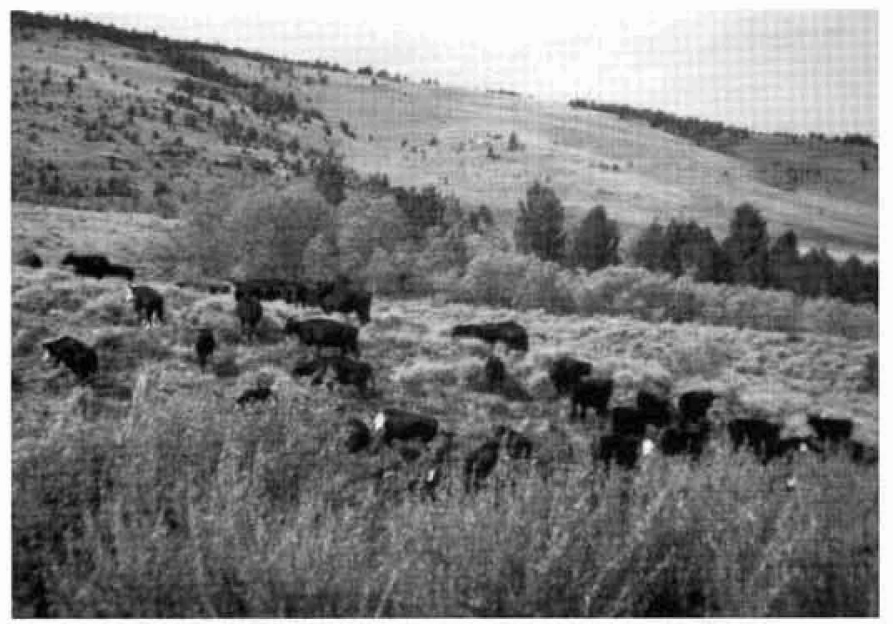

against fragmentation of habitats, loss of opportunity, and a chance to maintain and improve upon what we have now. In light of challenges to wildlife and natural things, these are the people who must become and be seen as the musicians and artists Leopold envisioned. No rancher wishes to become a "museum piece" in their lifetime, but they feel the pressures of extinction all too well.

Third, we must look at our ability to affect vast ecosystems beyond our borders. In that sense, economic uses which contribute to biological diversity, healthy streams and wetlands, and constantly changing upland ecosystems, may meet some of the world demand for food, fiber, and other goods, without sacrificing rain forests and other habitats under siege. A percentage of all beef eaten is consumed as ground beef supplied from areas where slash-and-burn tactics are viewed as the only alternative to poverty. If we produce an adequate supply of healthy, high-quality products on native rangelands, while at the same time conserving our ecological treasures, we might even be successful in aiding the brilliant songbirds at my window today when they venture south for winter.

\section{Using grazing animals to move in the de- sired direction can be an effective means of maintaining biological diversity, along with local cultures and economies.}

Using grazing animals as a tool (as well as an economic agent), the drawers of our tool box contain more magic than we might have thought. Number of animals, season of use, length of grazing period, type of animals, and other applications will derive different results. As we build programs of livestock use, we can look to pre-historic and recent historic records to guide us in managing for a variety of objectives. At Red Canyon, bison were probably not the main agent of change. There is some record of bison presence, but it was a fairly ephemeral occurrence, wandering bulls perhaps, or small bunches seeking shelter or escape. The primary animals noted on cave walls, and in the journals of trappers and explorers were more commonly elk, bighorn sheep, deer, and antelope. Of those, the elk and sheep were the herd animals most likely to shape the environment. In looking at animals which might mimic that activity, cattle have a fairly direct dietary overlap, and prefer similar habitats.

We know that big, native ungulates did not follow a plan derived by Lewis and Clark. Rather, they are responsive to natural events and occurrences which led to their foraging behavior. Predators, fire, drought, rain, lack of feed, and other natural factors moved the animals, probably imperfectly, across the landscape. We surmise that these animals had a range they preferred, and still see elk calving or wintering in the same safe havens. It is certain these animals did not avoid riparian and wetland habitats-they still favor those areas, much as most other species favor them. Consequently, in our design of grazing systems, one of the most important tools we can use to mimic natural disturbance is the amount of time animals spend in a given area.

We can enhance those habitats further by varying the season that animals are there, thus leading to a different plant response over the longer term. With children, we use a story about how plants think, how some of them see Spring as a time to grow as fast as possible, while others are content to lay in bed until it is really hot. If we don't toss change at these plants, they will quickly learn that their actions will create the same reaction-those which are eaten will give up and go away, leaving the landscape to those who are lazy. In time, a 


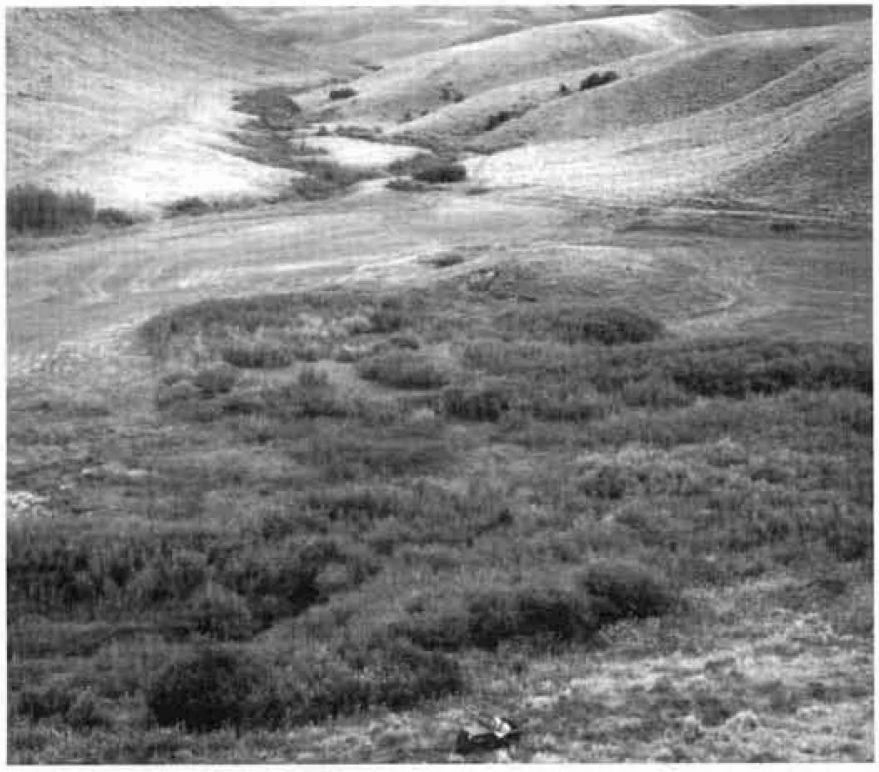

pasture used in Spring will become worthless for that purpose, blooming late in the year. The optimal result comes when we manage for diversity in all of our pastures.

When asked what we are trying to create by this management scheme, the answer is, "chaos and confusion!" This causes great consternation. We humans do things in our minds that lead us astray-one is to assume that the natural world should appear "pristine," a raked forest floor in a moody photograph. The natural world may be pristine, but it is not that photogenic. There is new growth, decay, erosion, floods, fire scars, and a world of successional variation on our landscape, and that will not be sustained if we insist upon a textbook example of mid-seral conditions. We must celebrate the fact that grazing animals can have an impact on these systems, an impact as natural as wind, rain, or fire. In some cases, we should look at grazing animals as keystone species that maintain or craft environments for others. Where we have discounted such interactions, we have sometimes paid the price dearly. In other systems animals are inappropriate tools, and we must admit that also.

There are two key areas animals can affect most rapidly in natural systems. The first is succession. By understanding diet, behavioral tendencies, and other characteristics, animals can be used, to favor or disfavor plants, often by impacting other vegetation. In the case of riparian and wetland systems, escaped brome seizes waterways through quick, early growth. By the time woody species have a chance to grow, they must compete with a four-foot canopy of dense grass in order to photosynthesize. The same reality can take place in a sedge meadow. By grazing these areas early in the season, as the native animals may have done, we can reduce canopies of brome or other undesirables and see sprouting of willow, birch, and other woody desirables increase laterally and within stands. Streams can narrow and deepen, and fisheries can produce trout as long as an eight-year-old's arm.

The key to management is to have as complete an understanding of the targets, goals, or objectives for the system of choice. Using grazing animals to move in the desired direction can be an effective means of maintaining biological diversity, along with local cultures and economies, but if we have no map of where to go we have merely luck and reaction to lead us.

Grazing animals may be essential integrators of energy within natural systems. In addition to the obvious contributions of dung and urine, animals can have a profound impact on energy tied up in vegetative systems. When we look at long term exclosures in conjunction with adjacent, grazed systems, we may find some unsettling realities. At the outset of rest, vegetation within exclosures released and began to flourish. For a number of years, it appeared as if exclusion was the cure. The area was assumed to be "healed." But, at some point long beyond that of a Master's or Doctorate program, many of these systems began to unravel. Woody vegetation became more scattered, characterized by older, perhaps less vigorous plants. Weeds occupied more of the areas. Measured differences began to confirm human observation, and ask questions of their own. Diversity of species appeared to be less, and occurrences of "less desirable" species more. Why is this happening? Perhaps it is a function of energy in natural systems, that field of science that so terrifies us due to lack of understanding and inability to see it work. Without agents to mobilize energy above- and below-ground, systems may reach points of stasis that become binding. Perhaps it is the stable states described by many in the research world. It appears that without challenge, disturbance, or outright energy release, many of the systems we seek to maintain will be crushed under their own weight. As this process occurs, other species may vacate, perhaps indicators that the system is in peril. We do not yet know these species of alarm, so must think of them all as "possibles," if possible, without overreacting. We do have time to figure these things out, but only if we approach the world as something we will not "save in our own time," instead as a mystery we can help our children to better comprehend.

The ideas presented here come more in the form of questions, than answers. Images and data may ultimately support some of these ideas, and refute others. If we truly wish to conserve the many species and communities we cherish in the West, we must find the will and wisdom to manage for those values. We must share them, and we must be both bold and patient. Within the hearts, minds, and hands of local people on the land lies the key to opportunity. Aldo Leopold said it best.

"The only progress that counts is that on the actual landscape of the back forty."

The author is the Director of Stewardship, Manager-Red Canyon Ranch, The Nature Conservancy Wyoming. 